\title{
RFID Kütüphane Sistemi İçin En Uygun RFID Etiketin AHP ve ANP Yöntemleriyle Belirlenmesi
}

\author{
Ramazan YENIGÜN ${ }^{1 *}$, Aytaç YILDIZ ${ }^{2}$, Levent UĞUR ${ }^{3}$ \\ ${ }^{1}$ Amasya Üniversitesi, Fen Bilimleri Enstitüsü, Teknoloji ve İnovasyon Yönetimi, Amasya \\ ${ }^{2}$ Bursa Teknik Üniversitesi, Mühendislik ve Doğa Bilimleri Fakültesi, Endüstri Mühendisliği Bölümü̈, Bursa \\ ${ }^{3}$ Amasya Üniversitesi, Teknoloji Fakültesi, Makine Mühendisliği Bölümü, Amasya \\ (ORCID: 0000-0003-1442-8019) (ORCID: 0000-0002-0729-633X) (ORCID: 0000-0003-3447-3191)
}

\section{$\ddot{O} \mathbf{z}$}

Kitaplar gibi çok sayıda nesnenin etiketlenmesi, tanımlanması ve sisteme işlenmesi oldukça zaman almaktadır. Radyo Frekansı ile Tanımlama (RFID ) teknolojisi, radyo frekansını kullanarak kitapların tanımlanması ve işlenmesi konusunda hızlı ve verimli bir yöntem sunmaktadır. Ancak birçok RFID teknolojisi arasından en uygun olanı belirlemek içerisinde birçok kriter barındıran karmaşık bir karar problemidir ve çok kriterli karar verme yöntemleri kullanılarak çözülmesi fayda sağlamaktadır. Bu çalışmada kütüphanedeki kitapların tanımlanması ve tüm süreçlerin kolaylaştırılması için kurulmak istenen RFID sistemi için önemli bir bileşen olan RFID etiketleri arasından en uygun olanını seçmek amaçlanmıştır. İlk olarak, belirlenen seçim kriterleri ve alternatiflere göre hiyerarşik ve ağ yapıları oluşturulmuştur. Daha sonra Analitik Hiyerarşi Prosesi (AHP) ve Analitik Ağ Prosesi (ANP) yöntemleri kullanılarak alternatifler sıralanmıştır. Çalışma sonunda her iki yöntemden elde edilen alternatif önem ağırlıklarına göre en uygun RFID etiketi tespit edilmiştir.

Anahtar kelimeler: Kütüphane sistemleri, RFID etiket, AHP, ANP.

\section{RFID Library System Determination by AHP and ANP Methods}

\begin{abstract}
It takes a lot of time to tag, identify, and processes a large number of objects such as books. Radio Frequency Identification (RFID) technology provides a fast and efficient way to identify and process books using radio frequency. However, it is a complex decision problem with many criteria for determining the most appropriate among many RFID technologies. And provide benefit by using multi-criteria decision making methods. In this study, it is aimed to select the most appropriate RFID tag which is an important component for the RFID system that is intended to be established in order to identify the books in the library and facilitate all the processes. First, hierarchical and network structures were established according to the selection criteria and alternatives identified. Then, alternatives were listed using Analytical Hierarchy Process (AHP) and Analytical Network Process (ANP) methods. At the end of the study, the most appropriate RFID tag was determined according to the alternative importance weights obtained from both methods.
\end{abstract}

Keywords: Library systems, RFID tag, AHP, ANP.

\section{Giriş}

Kütüphanelerde gerekli bilgilere zamanında ulaşılamaması, üye bilgilerinin sağlıklı bir şekilde kontrol edilememesi, kitap sayımının zaman alması ve kitapların gizemli bir şekilde ortadan kaybolması en sık rastlanan sorunlardandır. Kütüphane yönetimleri ise farklı yöntemler ve sistemler kullanarak okuyucuların isteklerine ve bu tür ortaya çıkan sorunlara çözüm aramaktadır. Bu sistemlerden biride Radyo Frekansı ile Tanımlama Teknolojisi (Radio Frequency Identification - RFID) sistemidir. RFID

*Sorumlu yazar: ramazanyenigun@hotmail.com

Geliş Tarihi: 09.07.2019, Kabul Tarihi: 05.12.2019 
teknoloji ile nesnelerin radyo ile otomatik olarak temassız ve net bir şekilde tanınmasını sağlanmaktadır [1]. Kütüphane yönetiminde RFID sistemi kullanılarak kütüphane materyallerine yapıştırılmış etiketlerdeki mikroçiplerde bulunan bilgiler, ürün yerleşimi veya hizalamasına bakılmaksızın radyo frekans teknolojisi kullanılarak okunur [2]. Bu teknoloji, kütüphane binasındaki kitapların izlenmesi, aranan kitapların hızlıca bulunması, okuyucuların bağımsız olarak kitap teslim etmesi ve alması, kütüphanecilerin çalışmalarının kolaylaştırması, kitap kabul etme ve yayınlama sürecindeki hataların ortadan kaldırmasına olanak sağlamaktadır. Ayrıca kitapların kütüphaneden izinsiz olarak alınmasına yönelik girişimleri engeller ve hırsılılk önleme işlevi görür [3].

$\mathrm{Bu}$ çalışmada, kütüphane otomasyon sistemi için önemli bir bileşen olan RFID etiketleri arasından en uygun olanı seçmek için çok kriterli karar verme yöntemlerinden AHP ve ANP kullanılmıştır. Yapılan çalışma beş bölümden oluşmaktadır. Çalışmanın ikinci kısımda RFID sistemi ve RFID etiketi ile ilgili bilgi verilmiştir. Üçüncü AHP ve ANP yöntemlerinden söz edilmiştir. Dördüncü bölümde AHP ve ANP yöntemiyle en uygun RFID etiket seçimi yapılmış olup son bölümünde sonuç ve değerlendirme yapılmıştır.

\section{Materyal ve Metot}

\subsection{RFID sistemi ve RFID etiket yapısI}

RFID, "radyo frekansı tanımlama" için kullanılan bir kısaltmadır ve RFID etiketlerinde veya akı1lı etiketlerde kodlanan dijital verilerin radyo dalgaları aracıllğıyla bir okuyucu tarafindan yakalandığı bir teknolojiyi ifade etmektedir [4]. RFID sistemi etiket ve okuyucu olmak üzere iki bölümden oluşmaktadır. RFID etiketleri bir verici ve bir alıcıya yerleştirilmiştir. RFID etiketlerinin bileşeninde bilgileri depolayan ve işleyen bir mikroçip ile sinyal almak ve iletmek için kullanılan bir anten vardır. Etiketler, belirli nesneler için belirli seri numarası içermektedir. Şekil 1'de gösterildiği gibi bir etikette kodlanmış bilgileri okumak için okuyucu adı verilen iki yönlü bir radyo vericisi-alıcısı, bir anten kullanarak etikete bir sinyal yayar. Etiket, hafizasında bulunan yazılı bilgilerle yanıt verir ve okuyucu daha sonra okuma sonuçlarını bir RFID bilgisayar programına iletir [5].

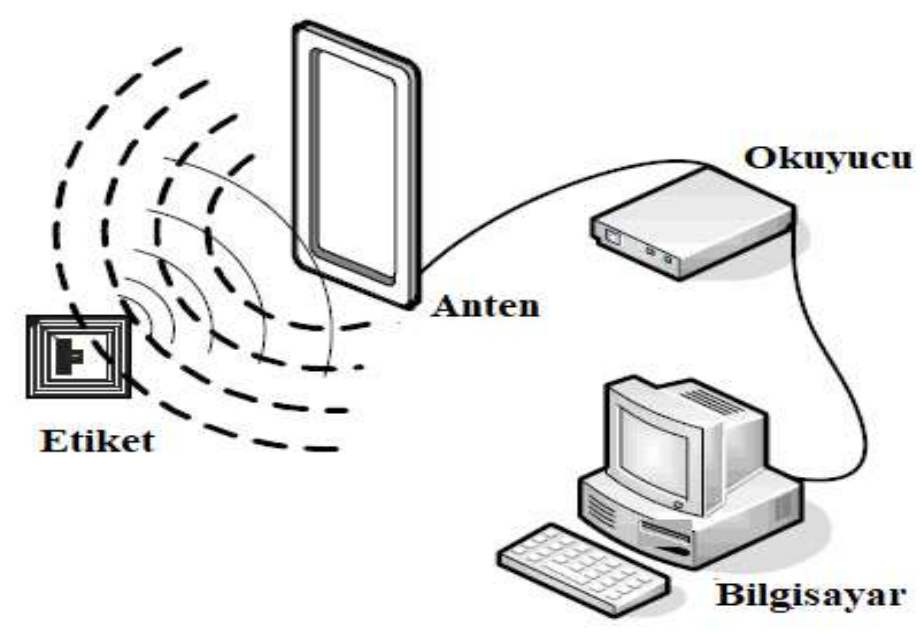

Şekil 1. RFID sistemi çalışması

RFID etiketi, içerisinde benzersiz şekilde tanımlama yapabilen, nesnelere ait bilgilerin depolandığı bir mikroçip biçiminde bellek ve okuyucuyla iletişime geçebilecek anten barındırır. Etiket kayıt alanına girdiğinde okuyucu tarafından okunur, gerekli durumlarda değiştirilebilir ve yeni bilgiler kaydedilebilir. RFID etiketleri ürün adı, ağırlığı, fiyatı ve okunmak istenen tüm bilgiler hakkında çeşitli bilgiler içerir. Okuyucu ile etiket arasındaki iletişim radyo frekansı sinyalleri ile sağlanır. Her etiket tanımlanması için benzersiz bir id numarası kullanılır. RFID etiketindeki mikroçip 64 bitten 8 MB'a kadar veri depolama özelliğine sahip olabilir. Bu da üzerinde bulunduğu nesnenin üretim, sevk tarihi, sipariş numarası, müşteri bilgileri, kurum personel bilgileri, seri numarası gibi önemli verileri kolayca taşıyabileceği anlamına gelmektedir [6-8]. Şekil 2'de RFID etiketinin yapısı gösterilmektedir. 

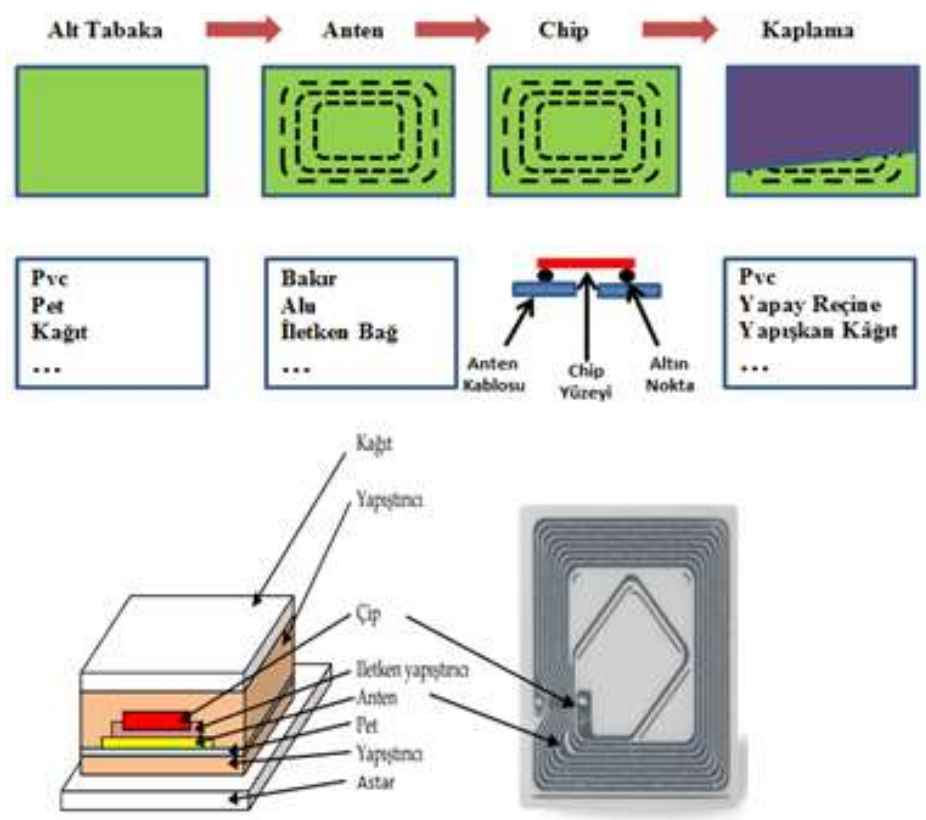

Şekil 2. RFID etiket yapısı [9]

Birinci tabaka genellikle kâğıttan veya polipropilenden yapılır ve koruyucu bir tabakadır. Bu katman altında erime ve basınca duyarlı olabilen yapışkan bir tabaka mevcuttur. Entegre devre veya çip anten ile epoksi bant yada macun gibi iletken yapıştırıcılar üzerinden bağlanabilir [9]. Anten, alüminyum veya bakırdan yapılmış ve bir plastik malzemeye tutturulmuştur. Son tabaka silikon kaplı bir kâğıt olan astardır ve bu tabaka diğer katmanlara yapışkanla bağlanır. Etiket yapımında kullanılan malzemeler uzun vadede güvenli kullanım açısından büyük önem taşır. Bu yüzden etiket tasarımcıları etiketin kullanılacağı şartlara göre etiketi en uygun yapıda tasarlamaları gerekir. Anten okuyucudan gelen radyo frekans1 (RF) dalgalarını alır ve yansıtır. Anten tasarımını uygulamanın frekansı ve etiketin boyutu belirler. Çip, etiketin işlevselliğini sağlar [10]. RFID etiketler enerji elde etme yöntemlerine, hafıza yapısına ve frekanslarına göre sınıflandırılmaktadır. Aşağıda bu sınıflandırılmalar kısaca açıklanmıştır.

\subsubsection{Enerji elde etme yöntemine göre etiketler}

Etiketler okuyucuyla irtibata geçebilmek için enerjiye ihtiyaç duyarlar. Bu enerji ihtiyacını ya kendi üzerlerinde bulunan bir güç kaynağından ya da okuyucudan elde ederler. Bu etiketlerden öne çıanlar; aktif, pasif ve yarı pasif RFID etiketleridir. Bu etiketlerin üretimi daha ucuz ve boyut olarak neredeyse tüm ürünlere sığabilecek düzeydedir [6].

\subsubsection{Aktif RFID etiketler}

Aktif sistemler tarafindan $433 \mathrm{MHz}$ ve $915 \mathrm{MHz}$ olarak kullanılan iki ana frekans vardır. Firmalar genellikle 433 MHz'de çalışan RFID sistemlerini tercih ederler. Çünkü metal ve su gibi rf dostu olmayan malzemelere karşı daha iyi çalışmasını sağlayan daha uzun bir dalga boyuna sahiptir [7]. Aktif RFID etiketleri temelde hem radyo vericisi hem de bir radyo alıcı devresi içermektedir. Kendi güç kaynağına sahiptir ve okuyucunun enerjisine bağlı değildir ve bunun sonucu olarak uzak mesafeden okunabilir. Ancak, bu tür etiketler pahalıdır ve pil ömrü sınırlıdır [8]. Aktif bir RFID etiketinin başlıca avantajlarını; son derece uzun okuma aralığı, ortak teknolojilerle artan etiket yetenekleri (GPS, sensörler, vb.), son derece sağlam etiket seçenekleri olarak sıralayabiliriz. Dezavantajları ise; etiketin ömrünü sınırlayan pil gücü olmadan çalışamaz, genellikle daha pahalıdır, fiziksel olarak daha büyüktür ve bakım maliyetleri fazladır [11].

\subsubsection{Pasif RFID etiketler}

Aktif RFID etiketlerinin aksine pasif RFID etiketlerinin anten ve bütünleşmiş devre olmak üzere sadece iki ana bileşeni vardır [7]. Adında anlaşılacağı gibi pasif RFID etiketleri herhangi bir güç kaynağına 
sahip değillerdir. Çalışması için gereken güç, okuyucu tarafından okuyucuya yaklaşıldığında sağlanır. Okuyucudan gelen bu enerji etiket anteninde bir gerilim indüklemesi oluşturarak etiketin bütünleşmiş devresini harekete geçirir. Bütünleşmiş devre içinde barındırdığı bilgiyi yine anten aracılığ 1 ile okuyucuya gönderir. Aktif bir RFID etiketinin aksine, pasif RFID kendi güç kaynağına sahip olmaması nedeniyle etiket okuyucusu etiketle iletişimi sağlamakla sorumludur [8]. Pasif bir RFID etiketi kullanımın avantajları; pilsiz çalışması, (yirmi yıl veya daha uzun bir ömrü vardır), üretim maliyetinin düşük olması ve çok küçük (bazı etiketler bir pirinç tanesi büyüklügündedir) olmasıdır. Dezavantajları ise; etiket sadece çok kısa mesafelerde tipik olarak en fazla birkaç metre uzakta okunabilir, elektrik ile çalışan sensörleri dâhil etmek mümkün olmayabilir, etiketin eklendiği ürün satıldıktan ve artık izlenmedikten sonra bile çok uzun bir süre okunabilir durumda kalır [12].

\subsubsection{Yarı pasif RFID etiketler}

Yarı aktif olarak da adlandırılan yarı pasif RFID etiketleri, pasif etiketlere çok benzer, ancak çipe güç sağlayan pillerle donatılmıştır [13]. Veri aktarımı pasif RFID etiketlere göre biraz daha hızlı olsa da çalışma mantığı aynıdır [10]. Aynı zamanda, bu işaretlerin menzili sadece okuyucunun hassasiyetine bağlıdır ve daha büyük bir mesafede ve daha iyi özelliklere sahip olarak işlev görebilir. Okuyucu tarafindan sorgulanmadan harekete geçmezler. Pasif etikete göre daha uzak mesafelerde iletişim sağlar ve maliyeti pasif etikete göre yüksektir [2]. Tablo 1'de enerji elde yöntemine göre etiketlerin özellikleri özet şeklinde verilmiştir.

Tablo 1. Enerji elde etme yöntemine göre RFID etiketler [12]

\begin{tabular}{|c|c|c|c|}
\hline Etiket Tipleri & Pasif & Yarı Pasif & Aktif \\
\hline Güç Kaynağı & RF aracığıyla okuyucudan alır & Batarya & Batarya \\
\hline İletişim & Sadece Yanit & Sadece Yanit & $\begin{array}{l}\text { Yanıt veri ve iletişime } \\
\text { geçebilir. }\end{array}$ \\
\hline Mesafe & $\begin{array}{l}\text { LF, HF: } 0,2 \mathrm{~m} \\
\text { UHF, SHF: } 3 \mathrm{~m} \\
\text { UWB: } 10 \mathrm{~m}\end{array}$ & $\begin{array}{l}100 \text { metreden daha uzak } \\
\text { mesafelerde }\end{array}$ & $\begin{array}{l}100 \text { metreden daha uzak } \\
\text { mesafelerde }\end{array}$ \\
\hline Maliyet & Düşük & Orta & Yüksek \\
\hline Örnek Uygulamalar & EPC, Yakın mesafe kartları & $\begin{array}{l}\text { Elektronik geçiş, Palet } \\
\text { izleme }\end{array}$ & $\begin{array}{l}\text { Büyük çapta mal izleme, } \\
\text { Hayvan takibi }\end{array}$ \\
\hline
\end{tabular}

\subsubsection{Hafıza yapısına göre etiketler}

RFID etiketleri ya salt okunur RFID etiketi olarak ya da okuma-yazma radyo frekansı tanımlama etiketi olabilir. Üretilen miktarlara ve bu ikisi arasındaki farklara karşı farklı türlerde üretim maliyeti göz önüne alındığında, günümüzde çoğu RFID etiketi, okuma yazma çeşitliliği ve sadece bir okuma işlevinin gerekli olduğu uygulamalar için yazma yeteneği kullanılmamaktadır [9]. Etiketleri hafıza yapısına göre 3'e ayırabiliriz.

\subsubsection{Sadece okunabilen etiketler}

Sadece okunabilen etiketler herhangi bir amaç için kullanılabilir. Tek fark, bu etiketlerin önceden kodlanmış olması ve verileri saklayabileceğiniz herhangi bir kullanıcı belleğinin olmamasıdır. Sadece okunabilen radyo frekans1 tanımlama etiketleri genellikle fabrikada programlanır. Veriler, değiştirilemeyen benzersiz bir tanımlayıcı ve diğer belirtilen bilgiler içerecektir. Önceden kodlanmış kimlik numarasıyla ilişkili öğeleri, kendiniz kodladığınız kimlikleri olan öğeleri izlediğiniz gibi takip edebilirsiniz [10]. Bu etiketlerin maliyetleri düşüktür ve ek belleği yoktur. 


\subsubsection{Hem okunup hem yazılabilen etiketler}

Hem okunup hem yazılabilen etiketler, kullanıcılara etiket üzerinde depolanan bilgileri güncelleme veya yeniden yazma yeteneği verir. Etiketin seri numarası gerektiğinde güncellenebilir, okuyucular da gerektiğinde etiket üzerine bilgi yazabilir. Bu etiketler salt okunur etiketlerden önemli ölçüde daha pahalıdır.

\subsubsection{Bir kez yazılıp birçok kez okunabilen (worm) etiketler}

Bir kez yazılıp, birden çok kez okunabilen (worm) etiketleridir. Bu etiketler kullanıcı tarafından bir kez kodlanabilir. Bundan sonra etiketler kilitlenir, bilgi saklanır ve değiştirilemez. Bu hem okunup hem yazılabilen etiketlerinden daha güvenli olma eğilimindedir [14].

\subsubsection{Frekanslarına göre etiketler}

RFID teknolojisin de bir dizi farklı frekanslar kullanılır. İşletme sahipleri ve yönetim ekipleri operasyonları için en uygun frekansı seçmeleri önemlidir. RFID sistemleri, Şekil 3'te gösterildiği gibi, çok farklı frekans bantlarında çalışırlar. Farklı frekanslar, farklı uygulamalar için onları daha kullanışı hale getiren farklı özelliklere sahiptir. Örneğin, düşük frekanslı etiketler daha az güç kullanır ve metalik olmayan maddelere daha iyi nüfuz edebilmektedir. Meyve gibi yüksek su içeriğine sahip nesneleri taramak için idealdir, ancak okuma aralıkları 3 metreden daha azıyla sınırlıdır. Yüksek frekanslı etiketler, metalden yapılmış nesneler üzerinde daha iyi çalışır ve yüksek su içeriğine sahip ürünler etrafında çalışabilir. Yaklaşık 1 metre okuma aralığı vardır. UHF frekansları genellikle daha iyi bir aralık sunmakla birlikte düşük ve yüksek frekanslardan daha hızlı veri aktarabilir. Fakat daha fazla güç kullanırlar ve materyallerden geçme olasılıkları daha azdır. Uygulamaların etkili çalışması için doğru frekansı seçmek çok önemlidir [15].
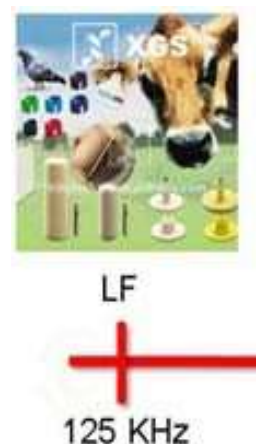
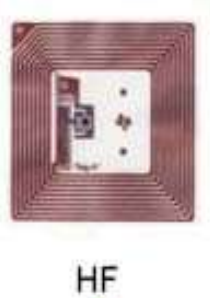

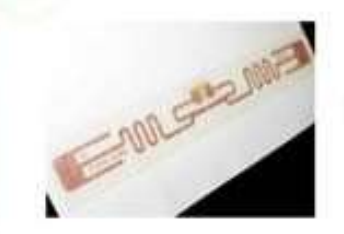

$\mathbf{\Lambda}$
UHF

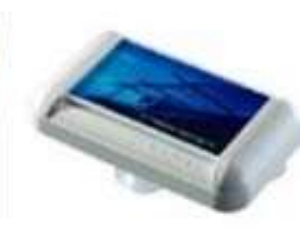

Microwave

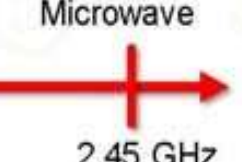

Şekil 3. RFID frekans aralıları ve tipik etiketlerin fotoğrafları [16]

RFID uygulamalarında en önemli detaylardan biride doğru etiketin seçimidir. Günümüzde RFID sistemi kurmak için yüzlerce etiket çeşidi mevcuttur. RFID etiket seçimi sisteme özel olarak yapılması verimli bir sistem kurulması açısından önemlidir. RFID etiket seçiminde dikkat edilecek noktalar aşağıdaki gibidir [12]:

- Etiketleme yapılacak yüzeyin durumu (metal, plastik, tahta vb. )

- İstenilen okuma mesafesi

- Etiket boyutunun büyüklüğü

- Çevresel koşullardaki aşırılık (aşırı sıcak, soğuk, nem vb.)

- Etiketin eklenme yöntemi (yapıştırarak, perçinleyerek vb.)

\subsection{AHP ve ANP yöntemi}

Hepimiz hayatın her alanında çeşitli kararlar vermek durumundayız. Bu kararlardan bir kısmı kolaylıkla verebildiğimiz kararlar iken bir kısmı daha fazla zorlandığımız, çok düşündügümüz ayrıntılı analiz 
gerektiren kararlardır. Karar vericilerin bu tür problemleri çözümünde kullanabileceği pek çok yöntem ve teknik bulunmaktadır. Bu teknikler sonlu sayıda seçeneğin birden fazla kritere göre değerlendirilmesi, karşılaştırılması, sıralanması ya da bunlar arasından en iyisinin seçilmesinde kullanılan çok kriterli karar verme teknikleri olarak ifade edilir. Unutulmamalıdır ki bir karar probleminde kriterler sayısal değerlerle ifade edilebilen nicel kriterler olabileceği gibi sayısal değerle ifade edilemeyen nitel kriterler biçiminde de olabilir.

Çok kriterli karar verme problemlerinin çözümünde yaygın olarak kullanılan yöntemlerden biri problemin çözümünde nitel ve nicel kriterleri birlikte ele alabilen Analitik Hiyerarşi Prosesi (AHP) yöntemidir [17]. Karar probleminin çözümünde sağladığı basitlik, esneklik ve kullanım kolaylığı sayesinde pek çok karar vericinin kullandığı bir tekniktir [18]. AHP kullanıcıları ilk olarak karar problemlerini, her biri bağımsız olarak analiz edilebilecek, daha kolay kavranan alt problemlerin hiyerarşisine dönüştürür [19]. Hiyerarşi bir kez oluşturulduktan sonra, karar vericiler kriterleri birbirleriyle karşılaştırarak sistematik olarak değerlendirirler [20]. Karş1laştırmalarda karar vericiler kriterler hakkında somut verileri kullanabilirler ama genellikle elemanların göreceli anlamı ve önemi hakkındaki yargılarını kullanırlar. AHP'nin özü, değerlendirmelerin yapılmasında sadece temel bilgilerin değil, insan kararlarının da kullanılabilmesidir [21]. Sürecin son aşamasında, karar alternatiflerinin her biri için sayısal öncelikler hesaplanmaktadır. Bu sayılar, alternatiflerin tercih edilme konusundaki göreceli yeteneğini temsil etmektedir [22]. AHP'de homojen elemanlar ikili olarak karşılaştırılmaktadır. Bu karşılaştırmalarda yargılar Tablo 2'de verildiği gibi 1-9 temel ölçeği kullanarak sayısallaştırılır. Karar vericinin sayısal bir ölçekten elde edilmiş gerçek değerlerin bilgisine sahip olması durumunda bu değerlerde ikili karşılaştırmalarda kullanılabilmektedir [17].

Tablo 2. İkili karşılaştırma ölçeği

\begin{tabular}{|c|c|c|}
\hline $\begin{array}{c}\text { Önem } \\
\text { Derecesi }\end{array}$ & Tanım & Açıklama \\
\hline 1 & Eşit derecede önem & İki faaliyet amaca eşit düzeyde katkıda bulunuyor. \\
\hline 3 & Orta derecede önem & $\begin{array}{l}\text { Tecrübe ve yargı, bir faaliyeti diğerine orta derecede tercih } \\
\text { ettiriyor. }\end{array}$ \\
\hline 5 & Kuvvetli derecede önem & $\begin{array}{l}\text { Tecrübe ve yarg1, bir faaliyeti diğerine kuvvetli derecede tercih } \\
\text { ettiriyor. }\end{array}$ \\
\hline 7 & Çok kuvvetli derecede önem & $\begin{array}{l}\text { Bir faaliyet güçlü bir şekilde tercih ediliyor ve baskınlığı } \\
\text { uygulamada rahatlıkla görülüyor. }\end{array}$ \\
\hline 9 & Mutlak derecede önem & $\begin{array}{l}\text { Bir faaliyet diğerine tercih edilmesine ilişkin çok güçlü kanıtlar } \\
\text { büyük güvenirliğe sahip }\end{array}$ \\
\hline $2,4,6,8$ & Ara değerler & Uzlaşma gerektiğinde kullanılmak üzere \\
\hline
\end{tabular}

İkili karşılaştırmalar matrisi AHP'de kriterler ve seçenekler için yapılır ve karşılaştırmada temel ölçekten yararlanılır. Bu ikili karşılaştırmalar amaca göre kriterler ve bu kriterlere bağlı olarak seçenekler için gerçekleştirilmektedir. Karar vericilerin karşılaştırmalarında tutarlı olmaları beklenir. Bununla birlikte karar vericilerin yargılarının tüm ikili karşılaştırmalarda tam bir tutarlık göstermesi beklenemez. Tutarsızlık belirli bir oranın altında ise (\%10) kabul edilebilirken bu oranın üzerine çıktığında karar vericiden ikili karşılaş̧ırma yargılarını tekrar gözden geçirmesi istenir [23]. Bu yüzden tutarlılık sorunuyla ilgili olarak AHP'de karar vericinin karşılaştırma sonuçlarına paralel olarak tutarlılık oranı (CR) hesaplanır [24].

AHP gibi literatürde karar verme problemlerinin çözümünde sıklıkla kullanılan yöntemlerden bir diğeri de ANP yöntemidir. Yöntem karar kriterleri arasındaki ilişkileri göz önüne alan ve karar problemine tek bir yöne bağlı kalarak modelleme zorunluluğunu ortadan kaldırır. Bu özelliği, AHP'ye göre daha hassas seçim yapma olanağ 1 vermektedir. AHP yönteminin devamı niteliğinde olan ANP yöntemi karmaşı karar verme süreçlerinde daha gerçekçi çözümler sunmaktadır. Yöntem karar verme sistemindeki her türlü etkileşimi, bağımlılığı ve geri bildirimi model içine katarak, bütün ilişkileri sistematik biçimde değerlendirmeye olanak sağlar. ANP yönteminde problem, Şekil 4 'te görüldüğü gibi AHP'den farklı olarak ağ yapısı kullanılarak modellenmekte, bu esnada tüm kriter kümelerindeki alt kriterler arasındaki bağımlılıklar ve her kriter kümesindeki alt kriterler arasındaki o kümeye ait içsel bağımlılıklar göz önüne alınmaktadır. ANP yönteminde AHP yaklaşımında olduğu gibi kriterlerin modele olan etkilerinin belirlenmesi için kriterlerin ikili olarak karşılaştırılması gerekmektedir [25]. 


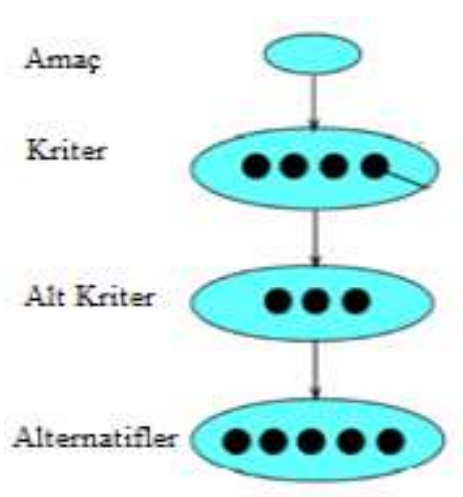

Hiyerarși Yapısı (AHP)

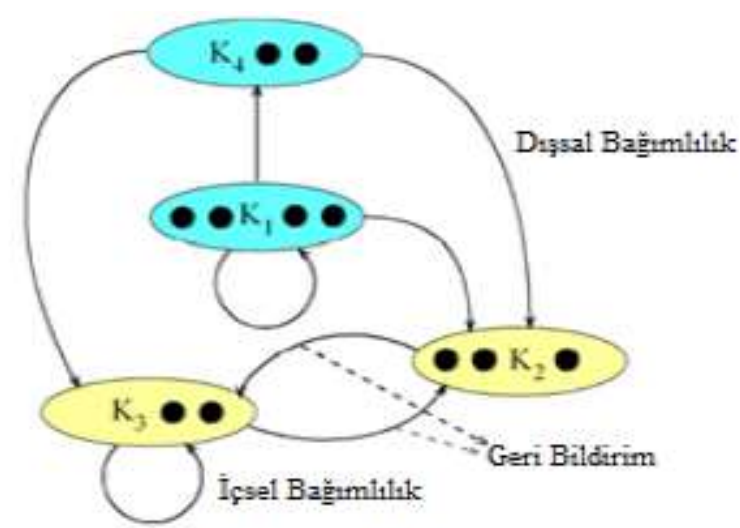

A ğ Yapısı (ANP)

Şekil 4. Hiyerarşi ve ağ yapısı [25]

\section{Yöntem}

Bu çalışmada, bir okulun kütüphanesindeki kitapların yönetimi için kurulması planlanan RFID sistemi için en uygun olan RFID etiketinin seçilmesi için ilk olarak AHP yönteminin aşağıdaki adımları kullanılmıştır.

\subsection{Hiyerarşik yapının oluşturulması}

Çalışmada ilk olarak en uygun RFID etiketinin seçilmesinde etkili olan kriterler literatür taraması ve okul yöneticilerinin görüşleri alınarak; fiyat, okunma hızı, veri depolama süresi, yazma dayanıklılığı, okunma aralığı, malzeme, bellek olarak tespit edilmiştir. Bu kriterlerin seçim probleminin çözümünde kullanılma sebepleri aşă̆ıda kısaca özetlenmiştir.

a) Fiyat: RFID etiket seçiminde tüketici için en ideal maliyetteki etiket seçilmelidir. RFID etiketi karar vericinin maliyetini karşılayabileceği bir fiyatta olmalıdır. Genellikle daha iyi performans gösteren RFID etiketler biraz daha maliyetli olabilir ancak bu seçim ileriye dönük büyük tasarruflara yol açabilir.

b) Okuma Hız: Bu kriterde zamandan tasarruf sağlanması amaçlanmıştır. Kitapların üzerine yapıştırılan etiketlerden okuyucuya gönderilen verilerin hızlı bir şekilde transfer edilmesi etiketin okuma hızı ile doğru orantılıdır. Okuma hızı yüksek olan RFID etiketi okuyucu tarafından daha hızlı okunur.

c) Veri Depolama Süresi: Veri depolama süresi kütüphanelerde uzun yıllar korunan kitapların doğru şekilde depolanması, işlenmesi ve değerlendirilmesi açısından büyük önem taşımaktadır. RFID etiketleri belirli bir süre sonra bilgileri depolama özelliğini kaybetmektedir. Kütüphanedeki kitapların çok uzun yıllar saklandığını düşünürsek veri depolama süresi uzun olan RFID etiketi diğer etiketlere göre daha avantajlidır.

d) Yazma Dayanıklıı̆̆ı: Yazma dayanıklılığı bütün RFID etiketler için yüksek öneme sahiptir. Etiketteki bilgiler tekrar tekrar güncellenerek, kullanılan nesne hakkında güncel bilgilere erişilebilir. Kütüphane üyelerinin ödünç alma işlemleri kitap etiketlerin üzerinden yapılabilir. Bu nedenle RFID etiket üzerine birçok kez veri yazılıp silinebilir. Yazma döngüsü yüksek olan RFID etiketler daha sık tercih edilir.

e) Okuma Aralığı: Okuma aralığı RFID sistemlerinin en önemli bileşenlerindedir. Kütüphanedeki kitaplara hızlı ve doğru bir şekilde ulaşılabilmesi için etiketlerin okuma aralığının geniş olmas1 gerekir.

f) Malzeme: Etiketin kullanım ömrü boyunca karşılaşabileceği çevresel koşullar, etiket seçiminde önemli hususlardır. Etiketin yapımında kullanılan malzeme etiketin ömrünün uzun olmasında büyük bir etkendir. Unutulmalıdır ki kitaplarda kullanılan etiketler yalnızca kütüphane içerisinde değil, kitapların ödünç verilmesiyle farklı çevre koşullarına maruz kalacaktır. Bu çevresel koşullar etiketin okuma aralığını veya okuma oranını etkileyebilir. Bu nedenle RFID etiket seçiminde malzeme seçimi göz ardı edilmemelidir. 
g) Bellek: Etiketin bellek boyutu, üzerine depolanacak veri miktarını etkiler. Çoğu RFID etiketinin üzerinde bulunduğu nesneyle ilgili bazı temel bilgileri depolamaya yetecek kadar 2 kilobayt kadar bir bellek boyutu vardır. Düşük maliyetle kurulan RFID sistemlerde yalnızca nesneyi tanımlayabilen salt okunur etiketler kullanılır. Bu tür sistemlerde nesne hakkındaki diğer ayrıntılı bilgiler kurulan veri tabanından elde edilir. Büyük hafızalara sahip etiketlere daha ayrıntılı kayıtlar yapılabilir.

Yukarıda açıklanan kriterlere göre satın alınması düşünülen etiket çeşitleri yine okul yöneticilerinin ortak görüşü doğrultusunda belirlenmiştir. Belirlenen kriterler ve alternatiflere göre seçim işleminin hiyerarşik yapısı Şekil 5'te verilmiştir.

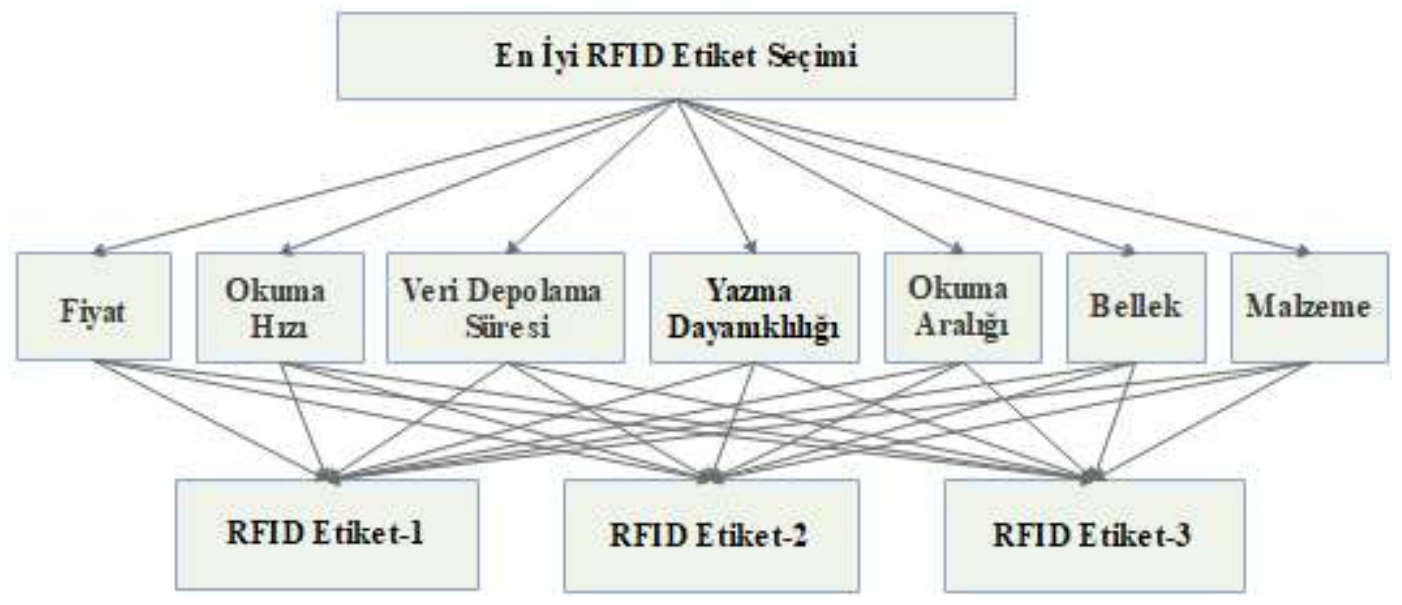

Şekil 5. RFID etiket seçimi probleminin hiyerarşik yapısı

\section{2. İkili karşılaştırma matrisinin oluşturulması}

Belirlenen kriterlerin kendi aralarında karşılaştırılması Tablo 2'de verilen 1-9 ölçeğine göre 3 okul yöneticisin ortak görüşüne göre değerlendirilmiş ve değerlendirme sonucu Tablo 3 'te verilmiştir. Ayrıca bu tabloda her bir kriter için önem ağılıklarının toplamı da hesaplanmıştır.

Tablo 3. Kriterlerin ikili karşılaştırma matrisi

\begin{tabular}{lccccccc}
\hline Kriterler & Fiyatı & $\begin{array}{c}\text { Okuma } \\
\text { Hızı }\end{array}$ & $\begin{array}{c}\text { Veri } \\
\text { Depolama }\end{array}$ & $\begin{array}{c}\text { Yazma } \\
\text { Dayanılılı̆̆ı }\end{array}$ & $\begin{array}{c}\text { Okuma } \\
\text { Aralığı }\end{array}$ & Malzeme & Bellek \\
\hline Fiyat & 1 & 5 & 7 & 7 & 5 & 6 & 3 \\
Okuma Hızı & $1 / 5$ & 1 & 4 & 4 & 1 & 3 & $1 / 3$ \\
Veri Depolama & $1 / 7$ & $1 / 4$ & 1 & 1 & $1 / 3$ & $1 / 2$ & $1 / 6$ \\
Yazma Dayanıkılı̆̆ı & $1 / 7$ & $1 / 4$ & 1 & 1 & 1 & $1 / 3$ & $1 / 5$ \\
Okuma Aralığı & $1 / 5$ & 1 & 3 & 3 & 1 & 2 & $1 / 5$ \\
Malzeme & $1 / 6$ & $1 / 3$ & 2 & 3 & $1 / 2$ & 1 & $1 / 5$ \\
Bellek & $1 / 3$ & 3 & 6 & 5 & 5 & 5 & 1 \\
\hline Toplam & 2,186 & 10,833 & 24,000 & 24,000 & 13,833 & 17,833 & 5,100 \\
\hline
\end{tabular}

\section{3. Öncelik vektörünün (kriter ağırlığı) hesaplanması}

$\mathrm{Bu}$ adımda öncelikli olarak her bir kriter için verilen değerlerin, sütun toplamına bölünerek normalizasyonu gerçekleştirilmiştir. Daha sonra normalize edilmiş matrisin her bir satırının aritmetik ortalaması alınarak öncelik vektörü hesaplanmış ve Tablo 4'te verilmiştir. Hesaplanan bu öncelik vektörü kriterlerin önem derecelerini göstermektedir. 
Tablo 4. Normalize edilmiş matris ve öncelik vektörü

\begin{tabular}{|c|c|c|c|c|c|c|c|c|}
\hline Kriterler & Fiyatı & $\begin{array}{c}\text { Okuma } \\
\text { Hizı }\end{array}$ & $\begin{array}{c}\text { Veri } \\
\text { Depolama } \\
\text { Süresi } \\
\end{array}$ & $\begin{array}{c}\text { Yazma } \\
\text { Dayanıklılığı }\end{array}$ & $\begin{array}{l}\text { Okuma } \\
\text { Aralığı }\end{array}$ & Malzeme & Bellek & $\begin{array}{l}\text { Öncelik } \\
\text { Vektörü }\end{array}$ \\
\hline Fiyat & 0,458 & 0,462 & 0,292 & 0,292 & 0,361 & 0,336 & 0,589 & 0,399 \\
\hline Okuma Hızı & 0,092 & 0,092 & 0,167 & 0,166 & 0,072 & 0,168 & 0,065 & 0,117 \\
\hline Veri Depolama & 0,065 & 0,023 & 0,042 & 0,042 & 0,024 & 0,028 & 0,033 & 0,037 \\
\hline Yazma Dayanıklılığı & 0,065 & 0,023 & 0,042 & 0,042 & 0,072 & 0,019 & 0,039 & 0,043 \\
\hline Okuma Aralığı & 0,092 & 0,092 & 0,125 & 0,125 & 0,072 & 0,112 & 0,039 & 0,094 \\
\hline Malzeme & 0,076 & 0,031 & 0,082 & 0,125 & 0,037 & 0,057 & 0,039 & 0,064 \\
\hline Bellek & 0,152 & 0,277 & 0,250 & 0,208 & 0,362 & 0,280 & 0,196 & 0,246 \\
\hline
\end{tabular}

Tablo 4'teki öncelik vektörüne bakıldığında RFID etiket seçiminde en etkili kriterin fiyat olduğu görülmektedir. Daha sonra sırasıyla bellek, okuma hızı, okuma aralığı, malzeme, yazma dayanıklılığı ve veri depolama süresi kriterleri yer almaktadır.

\subsection{Tutarlılık oranının hesaplanması}

Normalize edilmiş matrisin tutarlılık oranının tespiti için öncelikle tutarlıl1k indeksi hesaplanmış ve 0,100 olarak bulunmuştur. Daha sonra rassallık indeksi 1,35 (7 kriter için) alınarak tutarlılık oranı (CR) 0.044 olarak hesaplanmıştır. Bu değer 0.10 'dan küçük olduğundan, karar vericinin kriterlere ilişkin yargılarının tutarlı olduğu kabul edilmektedir.

\subsection{Alternatiflerin kriterlere göre karşılaştırılması}

Bu adımda her bir kriter tüm alternatifler için karşıllaştırılmıştır. Kriterlerin karşılaştırmasında malzeme kriteri hariç diğer kriterlerde sayısal değerler kullanıldığı için öncelik vektörü hesaplanmasında ikili karşılaştırma yapılmamıştır. Kriter değerleri belirlenen alternatif RFID etiketlerinin kataloglarından elde edilmiş ve Tablo 5'te verilmiştir.

Tablo 5. Alternatiflerin karşılaştırılması

\begin{tabular}{lcccccc}
\hline & $\begin{array}{c}\text { Fiyat } \\
\text { (Kuruş) }\end{array}$ & $\begin{array}{c}\text { Okuma Hızı } \\
(\mathbf{p c s} / \mathbf{s})\end{array}$ & $\begin{array}{c}\text { Veri Depolama } \\
\text { Süresi (Yıl) }\end{array}$ & $\begin{array}{c}\text { Yazma } \\
\text { Dayanıklılı̆̆ } \\
\text { 1 (Döngü) }\end{array}$ & $\begin{array}{c}\text { Okuma } \\
\text { Aralığı } \\
\text { (metre) }\end{array}$ & $\begin{array}{c}\text { Bellek } \\
\text { (Bit) }\end{array}$ \\
\hline RFID Etiket- & 65 & 50 & 20 & 200000 & 3 & 128 \\
\hline RFID Etiket- & 30 & 30 & 10 & 50000 & 10 & 512 \\
\hline RFID Etiket- & 50 & 50 & 50 & 100000 & 5 & 96 \\
\hline Toplam & 145 & 130 & 80 & 350000 & 18 & 736 \\
\hline
\end{tabular}

Tablo 5 'te fiyat kriterinde fiyatın artması ürünün tercih edilmesini olumsuz etkileyeceğinden dolayı gerçek fiyatın tersi alınarak normalize işlemleri yapılmıştır. Tablo 6'da ise 3 okul yöneticisinin ortak görüşü doğrultusunda tüm alternatifler malzeme kriteri için Tablo 2'deki ölçeğe göre ikili karşılaştırılmıştır ve aynı tabloda normalize işlemi yapılmıştır.

Tablo 6. Alternatif etiketlerin malzeme kriterine göre karşılaştırılması ve normalize matrisi

\begin{tabular}{lcccccc}
\hline Alternatifler & $\begin{array}{c}\text { RFID } \\
\text { Etiket-1 }\end{array}$ & $\begin{array}{c}\text { RFID } \\
\text { Etiket-2 }\end{array}$ & $\begin{array}{c}\text { RFID } \\
\text { Etiket-3 }\end{array}$ & \multicolumn{3}{c}{ Normalize Matris } \\
\hline RFID Etiket-1 & 1 & 3 & 7 & 0,678 & 0,706 & 0,583 \\
\cline { 1 - 4 } RFID Etiket-2 & 0,333 & 1 & 4 & 0,226 & 0,235 & 0,333 \\
\cline { 1 - 4 } RFID Etiket-3 & 0,142 & 0,25 & 1 & 0,096 & 0,059 & 0,084 \\
\hline Toplam & 1,476 & 4,25 & 12 & 1 & 1 & 1 \\
\hline
\end{tabular}

Hem nicel kriterler hem de nitel kriter olan malzeme kriteri için öncelik vektörü hesaplanarak Tablo 7'deki önem ağırlıkları elde edilmiştir. 
Tablo 7. Alternatif RFID etiketler için önem ağırlıkları

\begin{tabular}{lccccccc}
\hline & Fiyat & Okuma Hızı & $\begin{array}{c}\text { Veri Depolama } \\
\text { Süresi }\end{array}$ & $\begin{array}{c}\text { Yazma } \\
\text { Dayanıklılığı }\end{array}$ & $\begin{array}{c}\text { Okuma } \\
\text { Aralığı }\end{array}$ & Bellek & Malzeme \\
\hline RFID Etiket-1 & 0,224 & 0,385 & 0,250 & 0,571 & 0,167 & 0,174 & 0,656 \\
\hline RFID Etiket-2 & 0,485 & 0,231 & 0,125 & 0,143 & 0,556 & 0,696 & 0,265 \\
\hline RFID Etiket-3 & 0,291 & 0,385 & 0,625 & 0,286 & 0,278 & 0,130 & 0,079 \\
\hline
\end{tabular}

\subsection{Sıralama ve seçim aşaması}

Bu son adımda hem Tablo 4'teki kriter ağırlıkları hem de Tablo 7'deki ağırlıklardan oluşan Tablo 8' deki matris oluşturulmuştur. Nihai sıralamanın belirlenmesi için AHP matrisinde yer alan ağırlıklar satırı ile her bir kriter için hesaplanan değerlerin sütun çarpımıyla bir matris oluşturulmuştur (Tablo 9). Oluşturulan bu matriste her bir alternatife ait toplam değerler hesaplanarak sıralama yapılmıştır.

Yapılan AHP uygulaması sonucunda elde edilen ağırlık değerlerine göre kütüphane RFID sistemi için okul yöneticilerinin "RFID Etiket-2"yi tercih etmeleri daha uygun ve yararlı olacaktır. Çalışmada aynı problemim çözümünde ikinci bir yöntem olarak kriterler arası etkileşimi de dikkate alan ANP yöntemi uygulanmıştır. Yöntemde ilk olarak, fiyat kriterinin; diğer tüm kriterleri, okuma hızı; fiyat, okuma aralığı ve bellek kriterlerini, veri depolama süresinin; fiyat, malzeme ve bellek kriterlerini, yazma dayanıklılığının; fiyat, okuma hızı ve malzeme kriterlerini, bellek kriterinin; fiyat, veri depolama süresi ve okuma hızı kriterlerini ve malzeme kriterinin; fiyat ve yazma dayanıklılığ kriterlerini etkilediği belirlenmiştir. AHP yönteminde kullanılan model Super Decisions programında tekrar oluşturulmuş ve yukarıdaki etkileşimler de dikkate alınarak Şekil 6'daki ağ yapısı oluşturulmuştur.

Tablo 8. AHP ağırlıklar matrisi

\begin{tabular}{rccccccc}
\hline Kriter Ağırlıkları & $\mathbf{0 , 3 9 9}$ & $\mathbf{0 , 1 1 7}$ & $\mathbf{0 , 0 3 7}$ & $\mathbf{0 , 0 4 3}$ & $\mathbf{0 , 0 9 4}$ & $\mathbf{0 , 0 6 4}$ & $\mathbf{0 , 2 4 6}$ \\
\hline & Fiyat & Okuma Hızı & $\begin{array}{c}\text { Veri Depolama } \\
\text { Süresi }\end{array}$ & $\begin{array}{c}\text { Yazma } \\
\text { Dayanıklılığı }\end{array}$ & $\begin{array}{c}\text { Okuma } \\
\text { Aralığı }\end{array}$ & Malzeme & Bellek \\
\hline RFID Etiket-1 & 0,224 & 0,385 & 0,250 & 0,571 & 0,167 & 0,656 & 0,174 \\
\hline RFID Etiket-2 & 0,485 & 0,231 & 0,125 & 0,143 & 0,556 & 0,265 & 0,696 \\
\hline RFID Etiket-3 & 0,291 & 0,385 & 0,625 & 0,286 & 0,278 & 0,079 & 0,130 \\
\hline
\end{tabular}

Tablo 9. Alternatiflerin ağırlıkları ve sıralaması

\begin{tabular}{lcccccccccc}
\hline & Fiyat & $\begin{array}{c}\text { Okuma } \\
\text { Hızı }\end{array}$ & $\begin{array}{c}\text { Veri Depolama } \\
\text { Süresi }\end{array}$ & $\begin{array}{c}\text { Yazma } \\
\text { Dayanıklılı̆ı }\end{array}$ & $\begin{array}{c}\text { Okuma } \\
\text { Aralığı }\end{array}$ & Malzeme & Bellek & Ăğırlık Sıralama \\
\hline RFID Etiket-1 & 0,089 & 0,045 & 0,009 & 0,025 & 0,016 & 0,042 & 0,043 & 0,269 & 2 \\
\hline RFID Etiket-2 & 0,194 & 0,027 & 0,005 & 0,006 & 0,052 & 0,017 & 0,171 & 0,471 & 1 \\
\hline RFID Etiket-3 & 0,116 & 0,045 & 0,023 & 0,012 & 0,026 & 0,005 & 0,032 & 0,260 & 3 \\
\hline
\end{tabular}

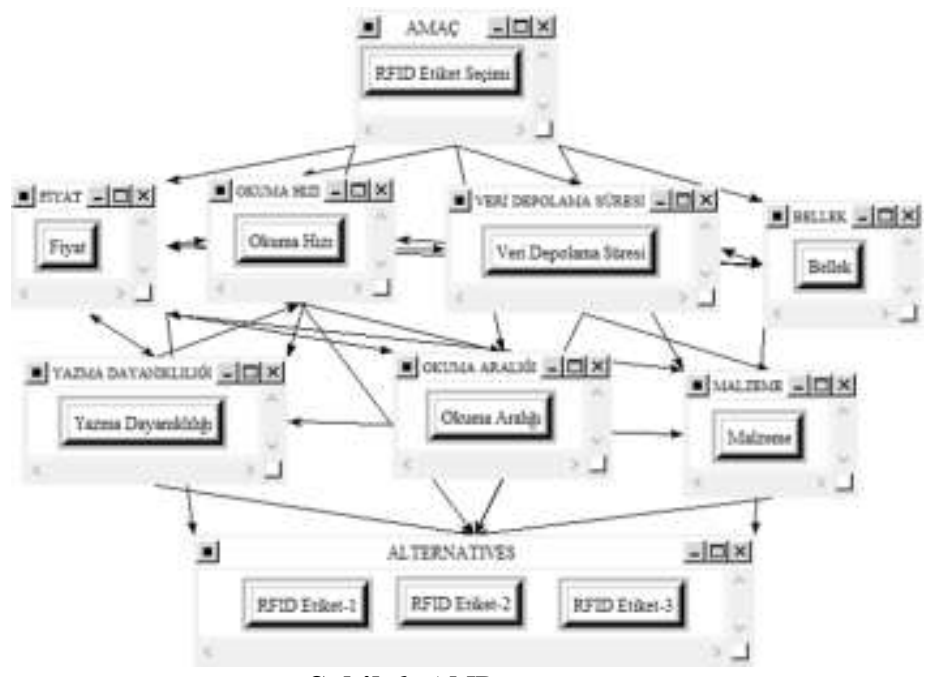

Şekil 6. ANP ağ yapısı 
AHP yönteminde kullanılan ikili karşılaştırmalara ek olarak yukarıda verilen kriterler arasındaki etkileşimler de dikkate alınarak ikili karşılaştırmalar yapılmış ve Tablo 10'da verilen kriter ağırlıkları elde edilmiştir.

Tablo 10. ANP yönteminden elde edilen kriter ağırlıkları

\begin{tabular}{|c|c|c|c|c|}
\hline$\$$ Sup & er Decisions Main Winc & ni_ANP.s... & $\times$ & \\
\hline \multicolumn{5}{|c|}{ Here are the priorities. } \\
\hline Icon & Name & $\longdiv { \text { Normalized by Cluster } }$ & Limiting & $\hat{1}$ \\
\hline No lcon & Bellek & 1.00000 & 0.145969 & \\
\hline No Icon & Fiyat & 1.00000 & 0.336515 & \\
\hline No Icon & Malzeme & 1.00000 & 0.039179 & \\
\hline No Icon & Okuma Aralığı & 1.00000 & 0.082232 & \\
\hline No Icon & Okuma Hızı & 1.00000 & 0.180061 & \\
\hline No Icon & Veri Depolama Süresi & 0.64035 & 0.070854 & \\
\hline No Icon & Yazma Dayanıklılığı & 0.35965 & 0.039795 & \\
\hline Okay $\mathrm{C}$ & opy Values & & & \\
\hline
\end{tabular}

Tablo 10 incelendiği zaman en önemli kriterin AHP yönteminde olduğu gibi fiyat, en az öneme sahip kriterin ise malzeme olduğu tespit edilmiştir. Tablo 11'da ise alternatif RFID etiketlerin önem ağırlıkları verilmiştir.

Tablo 11. Alternatif RFID etiketlerin önem ağırlıkları

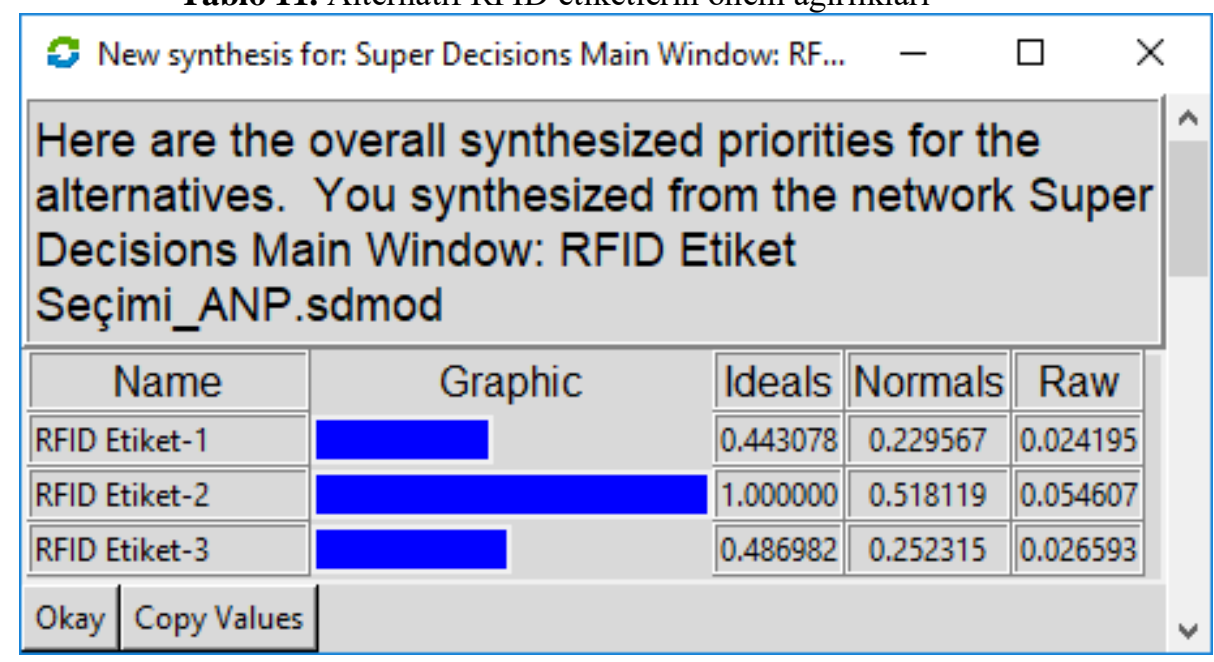

Tablo 11'daki normals değerlerine baktığımız zaman 0,518'lik önem ağırlı̆̆ ile RFID Etiket-2 alternatifi en iyi etiket olarak tespit edilmiştir. Son olarak, Şekil 7'de AHP ve ANP yöntemlerinden elde edilen sonuçların karşılaştırılması verilmektedir. Şekil 7'e bakıldığında her iki yöntemde de RFID Etiket-1'in önem ağırlığı en yüksektir. Bu yüzden bu etiketin kütüphane sistemi için seçilmesi uygun olacaktır. 


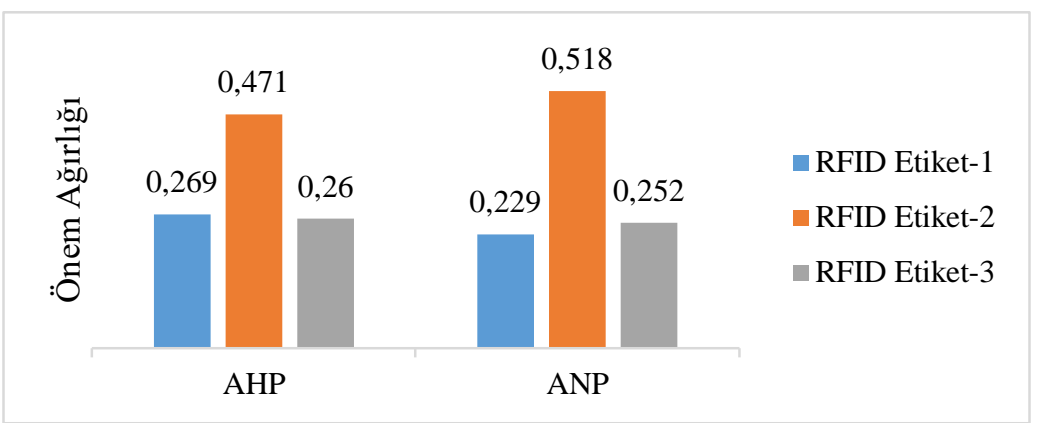

Şekil 7. AHP ve ANP'den elde edilen sonuçların karşılaştırılması

\section{Sonuç}

Radyo frekansı tanımlama veya RFID teknolojisi, dünyanın dört bir yanındaki işletmelerin üretim operasyonlarını iyileştirmelerinde, tedarik zincirlerini yönetmelerinde ve daha yüksek verimlilikle ürünlerini takip etmelerine olanak tanımıştır. Bu modern teknolojinin yaygın olarak benimsenmesi, işletme sahiplerinin üretimlerini ölçeklendirmelerine, maliyetlerini düşürmelerine ve daha önce hiç olmadığı gibi kârlarını artırmalarına olanak sağlamıştır. Ancak, RFID 'in faydalarını en üst düzeye çıkarmak için doğru tercihler yapmak gerekir. RFID teknolojisinin kullanım alanlarından biri olan kütüphane sistemi dünyada yaygın olarak kullanılmaya başlansa da ülkemizde maalesef yeterince uygulanmamaktadır. Bu sistemin kullanımının teşvik edilmesi kütüphanelerdeki verimliliğin artmasının yanı sıra eğitim ve hizmet kalitesinde de önemli artış sağlayacaktır.

RFID kütüphane sistemi kurulumunda önemli bir bileşen olan etiketin doğru seçimi oldukça önemlidir. RFID etiketleri arasında şekil ve kullanım açısından çok çeşitli farklılıklar görülmektedir. Çok sayıda seçeneğin ve kriterin bulunduğu böylesi bir ortamda tüketiciler RFID etiket seçiminde oldukça zorlanmaktadır. Diğer karar problemlerinde olduğu gibi bu problemin çözümünde de çok kriterli karar verme yöntemlerinin kullanılması karar vericiler üzerindeki zorlukları ortadan kaldırmaktadır.

Bu çalışmada, en uygun RFID etiket seçimi problemi için AHP ve ANP yöntemleri ile çözüm önerisi sunulmuştur. Önerilen çözümde nicel kriterlerin yanı sıra nitel kriterlerde dikkate alınmıştır. Literatür taraması ve okul yöneticileri ile yapılan görüşmeler sonunda RFID etiket seçiminde etkili olan 7 önemli kriter tespit edilmiştir. Oluşturulan hiyerarşik yapı için AHP ve ağ yapısı için ANP yöntemi uygulanmış ve alternatif etiketler sıralanmıştır. Her iki yöntemden elde edilen sonuçlar karşılaştırılmış ve her iki yöntemde de önem ağırlığı bakımından ilk sırada yer alan etiket satın alınacak en uygun etiket olarak tespit edilmiştir. Okul yöneticilerinin tespit edilen bu etiketi satın alması durumunda maliyet, okuma hızı ve okuma aralığı gibi çok önemli etiket kriterleri açısından optimum fayda sağlayacak ve kütüphane sistemlerinin verimli işlemesine olanak sağlayacaklardır.

\section{Yazarların Katkısı}

Çalışmaya yazarların katkısı eşit orandadır.

\section{Çıkar Çatışması Beyanı}

Yazarlar arasında herhangi bir çıkar çatışması bulunmamaktadır.

\section{Araştırma ve Yayın Etiği Beyanı}

Yapılan çalışmada araştırma ve yayın etiğine uyulmuştur.

\section{Kaynaklar}

[1] Wamba S.F., Lefebvre E., Bendavid Y., Lefebvre L. 2008. From automatic identification and data capture (aidc) to "smart business process": preparing for a pilot integrating RFID. RFID Handbook: Applications, Technology, Security and Privacy, CRC Press. 
[2] Library RFID system. 2019. https://www.RFID-library.com/ (Erişim tarihi:15.02.2019).

[3] What is RFID (radio frequency identification) technology? 2019. https://www.bibliotheca.com/library-RFID-technology/. (Erişim tarihi:19.11.2019).

[4] What is RFID? 2019. https://www.abr.com/what-is-RFID-how-does-RFID-work/(Erişim tarihi: 21.03.2019).

[5] Code B. 2018. How does a RFID system work?, https://www.epc-RFID.info/RFID. (Erişim tarihi:14.03.2019).

[6] Roberts C.M. 2006. Radio frequency identification (RFID). Computers \& security, 25 (1): 18-26.

[7] Jones A.K., Dontharaju S., Tung S., Hawrylak P.J., Mats L., Hoare R., Mickle M. 2006. Passive active radio frequency identification tags. International Journal of Radio Frequency Identification Technology and Applications, 1 (1): 52-73.

[8] Sarma S., Brock D., Engels D. 2001. Radio frequency identification and the electronic product code. IEEE Micro, 6: 50-54.

[9] Yüksel M.E., Zaim A.H. 2009. RFID’nin kablosuz iletişim teknolojileri ile etkileşimi. Akademik Bilişisim, 11-13.

[10] Repanovici A., Cristea L. 2011. RFID-application in info-documentary systems. In Designing and Deploying RFID Applications. InTECH.

[11] Technovelgy. Aktif RFID Etiketi, http://www.technovelgy.com/ct/TechnologyArticle.asp?ArtNum=21. (Erişim tarihi:17.02.2019).

[12] Solutions A.R. The basics of an RFID system, http://RFID.AtlasRFIDstore.Com/HsFs/Hub/300870/File-252314647 (Erişim tarihi:19.03.2019).

[13] RFID: Doğru seçim hangi frekans? https://www.Advancedmobilegroup.Com/Blog/Rfid WhichFrequencyİsTheRightChoice. (Erişim tarihi:03.02.2019).

[14] Salt okunur rfid etiketleri ne için kullanılır? 2019. https://www.Rfidjournal.Com/Blogs/Experts/Entry?11873. (Erişim tarihi:22.03.2019).

[15] Salt okunur ve okuma-yazma RFID etiketleri arasındaki fark nedir? https://www.Rfidjournal.Com/Faq/Show?67. (Erişim tarihi:13.01.2019).

[16] Başvurum için hangi frekansın doğru olduğunu nasıl bilebilirim? https://www.Rfidjournal.Com/Faq/Show?61. (Erişim tarihi: 14.03.2019).

[17] Kadak E.G. 2006. Türkiye' de AHP tekniğinin performans değerlendirmedeki yeri ve ilaç dağıtım sektöründe uygulanması. Yüksek Lisans Tezi, Çukurova Üniversitesi Fen Bilimleri Enstitüsü, Adana.

[18] Haliloğlu M., Odabaş M.S. 2017. Çok ölçütlü karar vermede AHP yöntemi. Kilis 7 Aralık Üniversitesi Fen ve Mühendislik Dergisi, 2 (2): 13-18.

[19] Enis Ö.S. 2010. Denetim evreninin belirlenmesinde alternatif bir yöntem: Analitik hiyerarşi prosesi. Denetişim, 4: 8-16.

[20] Özyörük B., Özcan E.C. 2008. Analitik hiyerarşi sürecinin tedarikçi seçiminde uygulanmasi: otomotiv sektöründen bir örnek. Süleyman Demirel Üniversitesi İktisadi ve İdari Bilimler Fakültesi Dergisi, 13 (1): 133-144.

[21] Saaty T.L., Vargas L.G. 1987. Uncertainty and rank order in the analytic hierarchy process. European Journal of Operational Research, 32 (1): 107-117.

[22] Saaty T.L. 2008. Relative measurement and its generalization in decision making why pairwise comparisons are central in mathematics for the measurement of intangible factors the analytic hierarchy/network process. RACSAM-Revista de la Real Academia de Ciencias Exactas, Fisicas y Naturales. Serie A. Matematicas, 102 (2): 251-318.

[23] Saaty T.L. 1990. How to make a decision: the analytic hierarchy process. European journal of operational research, 48 (1): 9-26.

[24] Weis S.A. 2007. RFID (radio frequency identification): Principles and applications. System, 2 (3): $1-23$.

[25] Yıldız A. 2014. En iyi üniversite seçiminde analitik ağ prosesinin kullanımı. İleri Teknoloji Bilimleri Dergisi, 3 (2): 108-119. 